\title{
FRONTEIRAS DA RELIGIÃO: A COMUNICAÇÃO NO INSTAGRAM ENTRE O PAPA FRANCISCO E AS MULHERES
}

\author{
Frontiers of religion: the communication on Instagram between \\ Pope Francis and women
}

\section{Las fronteras de la religión: comunicación en Instagram entre Papa Francisco y las mujeres}

\author{
Cláudio de Musacchio \\ Portal EAD Brasil, Rio Grande do Sul, Brasil. \\ Doutor pelo Programa de Pós-Graduação em Informática na Educação da Universidade Federal do Rio Grande \\ do Sul. Mestre em Educação pela Ulbra. Pós-graduado em Engenharia de Software pela Estácio de Sá-RJ. CEO \\ e founder do Portal EAD Brasil. Criador dos cursos Facebook na sala de aula e Web rádio na educação. \\ E-mail: musacchio@portaleadbrasil.com.br
}

\section{Jociane Marchesan Oling}

Pontifícia Universidade Católica do Rio Grande do Sul, Rio Grande do Sul, Brasil.

Publicitária pela Universidade Regional do Noroeste do Estado do Rio Grande do Sul, pós-graduada em Marketing Primeira Gerência pela Escola Superior de Propaganda e Marketing do Rio Grande do Sul e mestranda do Programa de Pós-Graduação em Comunicação da Pontifícia Universidade Católica do Rio Grande do Sul.

E-mail: jocianet@hotmail.com

RESUMO Este trabalho analisa qualitativamente a comunicação do Papa Francisco na mídia digital, mais precisamente no aplicativo Instagram considerando seu conteúdo, objetivos, formas de abordagem e a relação com algumas fundamentações teóricas. A análise foi desenvolvida a partir de vídeos e fotos no perfil @franciscus do aplicativo. Em relação ao público, fez-se um recorte para analisar a repercussão dessa comunicação no público feminino observando alguns comentários de dois vídeos específicos. O aporte teórico obteve a contribuição epistemológica de Douglas Kellner, Roberto Tietzmann, além de outros pesquisadores. Como embasamento metodológico, foi utilizada a técnica da análise de conteúdo a partir de Laurence Bardin, Christian Laville e Jean Dionne. E os resultados preliminares indicam sinais de que Papa Francisco atinge seus objetivos obtendo suporte dos recursos digitais para expandir sua comunicação evangelizadora.

PALAVRAS-CHAVE Comunicação, Mídia digital, Instagram, Papa Francisco, Religião.

\begin{abstract}
This study analyzes qualitatively Pope Francis's manner of communication in digital media, more precisely on the digital application Instagram, considering his contents, goals, approaches and the relationship with some theoretical foundations. The analysis was developed based on videos and pictures in the@franciscus profile of the application. In relation to the public, the impact of this communication on the female audience was analyzed through the observing of some comments in two specific videos. The theoretical foundations included the epistemological contribution of Douglas Kellner, Roberto Tietzmann, in addition to other researchers. As a methodological basis, the technique of content analysis was used based on Laurence Bardin, Christian Laville and Jean Dionne. Preliminary results indicate signs that Pope Francis achieves his goals by obtaining support from digital resources to expand his evangelization.
\end{abstract}

KEYWORDS Communication, Digital media, Instagram, Pope Francis, Religion. 
RESUMEN En este estudio se analiza cualitativamente la comunicación del Papa Francisco en los medios digitales, especialmente en la aplicación Instagram, sus contenidos, objetivos, formas de abordajes y la relación con el marco teórico. En el análisis se utilizaron videos y fotos publicadas en el perfil @franciscus en Instagram. En cuanto al público, se hizo un recorte para analizar la repercusión de la comunicación entre el público femenino mediante la observación de mensajes en dos videos específicos. El marco teórico utilizado contó con Douglas Kellner, Roberto Tietzmann, entre otros investigadores. Como metodología se utilizó el análisis de contenido desde las obras de Laurence Bardin, Christian Laville y Jean Dionne. Los resultados apuntan que el Papa Francisco logra sus objetivos al utilizar como soporte los recursos digitales para ampliar su comunicación evangelizadora.

PALABRAS CLAVE Comunicación, Medios digitales, Instagram, Papa Francisco, Religión.

\section{INTRODUÇÃO}

A mídia digital vem conquistando seu espaço quando se refere à interação e proximidade entre grupos, estando a cada dia mais presente no cotidiano social como instrumento de comunicação. E não só entre indivíduos e grupos anônimos, mas também entre empresas, instituições, grupos sociais e religiões estão usufruindo-se dessa era interativa. E as vertentes midiáticas conectam entre si, estabelecendo uma cultura de convergências em que uma só mídia é possível viabilizar outras, como imagens da televisão, o som do rádio, conteúdos impressos semelhantes a revistas e jornais etc. Isso possibilita ao usuário uma interatividade instantânea, surgindo uma nova cultura, novos valores e recursos.

Nesse contexto, o Papa Francisco tem buscado maior aproximação com a sociedade. Com uma linguagem mais popular e acessível, ele propõe uma nova comunicação entre o catolicismo e o público, considerando que a instituição vem perdendo seguidores dia após dia. Com base nisso, o estudo busca investigar empiricamente o uso dos meios de comunicação e da mídia digital pelo catolicismo, especialmente por Papa Francisco. E como objeto, aborda-se a interatividade do líder religioso em dois materiais audiovisuais com mulheres seguidoras do perfil @franciscus no aplicativo Instagram.

Inicia-se a reflexão apresentando conceitos, um breve histórico da Igreja Católica e dos meios de comunicação. Também, a relação de Francisco com as mídias, especialmente a digital e a análise do perfil @franciscus, fazendo um recorte em dois vídeos publicados. Serão apresentados analiticamente o conteúdo, a forma de abordagem, os comentários dos seguidores e as demais argumentações essenciais para a análise dessa mudança de fronteiras ocorrida em virtude da nova era digital. E a proposta metodológica mais adequada para este estudo foi a análise de conteúdo.

Busca-se verificar o desencadeamento desse processo de expansão da informatização, quais mudanças são observadas no catolicismo, suas características e um breve resultado sobre a recepção do público feminino. E para responder a essas indagações, propõe-se utilizar o grande pensador da Era da Informação, Manuel Castells, além de Douglas Kellner, Luiz Antônio Coelho, Roberto Tietzmann, Miriam Rossini, bem como outros autores relacionados, matérias e cases para exemplificar o tema.

\section{PROCEDIMENTOS METODOLÓGICOS}

Para dar sustentação a este estudo, optou-se pelo método da análise de conteúdo, baseando-se nos conceitos de Bardin, Laville e Dionne. 
Ocorre que esse método não cumpre etapas delimitadas, mas reconstrói, na prática, as observações do pesquisador. Bardin (2009) define análise de conteúdo como um conjunto de técnicas de análise de comunicações, com procedimentos sistemáticos e objetivos de descrever o conteúdo das mensagens.

Laville e Dionne (1999) contribuem para que a análise de conteúdo seja aplicada essencialmente aos dados apresentados como discurso, incluindo textos retirados de documentos como respostas de perguntas abertas.

Na realidade, um longínquo trabalho de análise já foi iniciado com a coleta dos materiais e a primeira organização, pois essa coleta, orientada pela questão da hipótese, não é acumulação cega ou mecânica: à medida que colhe informações, o pesquisador elabora sua percepção do fenômeno e se deixa guiar pelas especificidades do material selecionado. (LAVILLE; DIONNE, 1999, p. 215)

Bardin (2009) apresenta o desenvolvimento da análise de conteúdo em três fases fundamentais: a pré-análise, formato com experimentos bem delimitados; exploração do material, que consiste na tomada das decisões anteriormente apresentadas; e o tratamento dos resultados, que obtém dados como referência e os transforma em resultados significativos e pertinentes.

Tendo utilizado essa fundamentação como base, os dois vídeos com seus comentários no perfil @franciscus do aplicativo Instagram foram fragmentados na seguinte ordem:

a) Pré-análise: esta etapa configurou-se na leitura analítica do material como a localização, períodos, repercussão de todos os materiais do perfil, a visualização das fotos, vídeos, descrições e comentários. Nessa mesma fase foi determinado o corpus da análise. Foram escolhidos o primeiro e o quarto vídeo seguindo critérios como o número de visualizações, o conteúdo do vídeo e os comentários de seguidores.

b) Exploração do material: Nesta fase, ocorreu o levantamento das informações e a descrição dos conteúdos em concomitância com as referências. Em paralelo, a análise das abordagens audiovisuais e seus comentários.

c) Tratamento dos resultados: Esta etapa consistiu nas interpretações e inferências coletadas nas etapas anteriores, considerando a perspectiva qualitativa. Foram examinados e interpretados os dados dos dois vídeos e, a posteriori, realizada uma descrição comparativa e analítica do corpus.

Após pormenorizar as etapas metodológicas da análise de conteúdo, contextualizou-se o objeto deste estudo, examinando os conceitos de comunicação do Papa Francisco no aplicativo Instagram.

\section{MÍDIAS E RELIGIÃO CATÓLICA: FRONTEIRAS E RELAÇÕES CULTURAIS}

Com a Revolução Industrial e o avanço capitalista a partir do século XVIII, surgiu uma sociedade globalizada e fronteiras na comunicação, estabelecendo relações rápidas e diretas na informação entre emissor e receptor. A evolução dos meios de comunicação de massa, as tecnologias, a informatização e a nova comunicação em rede colaboram para esse processo. 
No ambiente virtual surgiu uma nova forma de viver em sociedade e uma inédita compreensão de espaço-tempo, facilitando assim o acesso à transformação e ao surgimento de novos canais. Há quem defenda que essas tecnologias são prejudiciais, sob a perspectiva de que, com seus adventos, o indivíduo venha diminuir seu convívio social. Mas há também opiniões favoráveis, observando suas vantagens no ambiente da comunicação e da religião apesar das diversidades vinculadas às quebras de fronteiras culturais.

Desde o surgimento dos meios de comunicação de massa, a Igreja Católica tem utilizado a mídia como um de seus principais recursos de evangelização. Isso manifesta consigo uma nova maneira de relacionarse com o público fiel. Douglas Kellner (2001) sustenta que a mídia é valorizada pela sociedade, tanto que cria modelos de comportamentos e modifica culturas. $\mathrm{E}$ as instituições religiosas utilizam-se desse ambiente para conquistar seus devotos.

Para começar, a cultura da mídia põe à disposição imagens e figuras com as quais seu público possa identificar-se, imitando-as. Portanto, ela exerce importantes efeitos socializantes e culturais por meio de seus modelos de papéis, sexo e por meio das várias "posições de sujeito" que valorizam e denigrem outros tipos. (KELLNER, 2001, p. 307)

Tal reflexão busca entender as razões dessa mudança no ambiente cultural e religioso especialmente diante da mulher, corroborada ou não pela mídia digital. Entender esse processo é relevante à medida que ameaça interferir no comportamento do fiel, na maneira de conviver em sociedade, sobretudo, nas mudanças de vida em geral, as quais muitos sequer percebem. Uma análise com bases aplicáveis em qualquer setor ou local deste país, seja no ramo da comunicação, da sociologia, antropologia, da teologia ou da religião.

As consequências das redes e da informatização não parecem ainda ser claras, visto que estão em transformação. Tomado como referência dessa evolução conectiva, Manuel Castells (1999) atribuiu um novo nome à internet, designando-a como sociedade em rede. Para ele, sua compreensão é baseada num conjunto de diversos grupos que se comunicam simultaneamente, sob os quais não são identificados somente em hardwares, computadores ou telas interativas, mas também pessoas, visto que a própria informação faz parte dessa coletividade. Um exemplo de proximidade e interatividade no âmbito da religião é o uso das redes sociais por líderes católicos e a facilidade de comunicação que essa mídia proporciona entre eles e seus fiéis. As redes não são somente conexões superficiais, mas a globalização contribui para conectar e desconectar indivíduos em sua cultura e religião de maneira contínua e progressiva.

Na sociedade contemporânea, a expansão de novas mídias converge-se com as mídias tradicionais numa nova velocidade, provocando estudos no campo da comunicação, ultrapassando limites e explorando inúmeras possibilidades dos meios midiáticos, incluindo a televisão. "A internet já transformou a televisão" (CASTELLS, 1999, p. 11).

As mídias tradicionais surgem em novos dispositivos, especialmente no aparelho celular, e consequentemente modificam suas produções, surgindo uma nova concepção. Os conteúdos transferem-se de locais fixos para acompanhar o sujeito em suas atividades. Esse meio é caracterizado como uma maneira de interligação composta por uma rede de conexões entre a arte e a comunicação, denominada interface. 
A relação com o tempo e o acontecimento do audiovisual é modificada quando passa do controle de imagens gravadas e editadas para a liberdade da transmissão em tempo real, da transmissão ao vivo e do improviso. Esse novo formato é reforçado em inúmeros de materiais audiovisuais nas redes sociais e aplicativos.

Sobre o significado de interface, Luiz Antônio Coelho (2008, p. 208) aponta que:

A ideia básica de interface sugere uma superfície limítrofe entre dois corpos ou espaços. A interface, no entanto, vai além de uma simples separação; indica a possibilidade de adaptação, de interconexão, de comunicação entre dois ou mais sistemas, equipamentos, unidades, etc. que, de alguma forma, apresentem diferenças ou incompatibilidades funcionais.

Essa mudança entre produtor de conteúdo e receptor na interface do vídeo on-line conduz a uma transição de papéis entre amadores e profissionais a tal ponto que o trabalho tradicional profissional acabou perdendo força. A apreciação por conteúdo curto, não-narrativo e amador obrigou o profissional a imitar esse formato para ser percebido e valorizado.

For this reason, professional products try to imitate the 'amateur look and feel' in order to be perceived as authentic. In addition to this, amateur products have spread to classic mass media as their success, uniqueness, and authenticity have become a subject of interest for news coverage or editorials. (MAREK, 2011, p. 207)

Observa-se não somente a mudança de papéis, mas também a aceitação do público pelo não-narrativo e amador. E na releitura de formatos tradicionais, um rompimento de fronteiras na experiência do acontecimento e da estética audiovisual, apresentados por Tietzmann e Rossini (2013, p. 7):

O panorama da comunicação audiovisual contemporânea do início do século XXI pode ser entendido, portanto, como um mosaico fragmentado de produtores amadores, coletivos e profissionais; de canais múltiplos através dos quais circulam não apenas modelos e formatos tradicionais, mas também releituras de formatos antigos possibilitados por novas ferramentas digitais. Neste contexto destacamos a onipresença de vídeos que denominamos audiovisuais de acontecimento, fruto da ubiquidade de câmeras digitais e de canais que facilitam a circulação desses produtos.

Ao obter esse panorama de mudanças culturais, tanto na relação da mídia com o público, incluindo a mulher, quanto entre as próprias mídias, compreende-se que os recursos do audiovisual e da internet em especial adotam novas posturas. Essas propagam possibilidades de interatividade entre fiéis e a Igreja, não abandonando a presença física ao templo, mas possibilitando novas formas de alcance no mercado da religião. Apesar de não ter contato físico, além de proporcionar comodidade, as experiências virtuais da fé nesse novo recurso transmitem o conforto espiritual que fiel necessita. E nessa liberdade de tempo-espaço, ele pode escolher o momento apropriado para acessar determinado conteúdo disponível na rede, especialmente em situações de dificuldades ou apenas para proporcionar uma sensação de bem-estar. 
Esse acompanhamento de inovações por parte da Igreja Católica não é um acontecimento necessariamente novo ao considerar sua história e evolução. Foi uma das precursoras no exercício da imprensa e dos meios de comunicação. Tanto que hoje ela adapta-se progressivamente a esse universo. Em termos históricos, pode-se observar com as Cruzadas expedicionárias entre os séculos XI e XIII (SILVA, 2006), as quais incentivaram a evangelização católica e seus rituais na região europeia e oriental. Para eles, essa fase foi considerada a fronteira inicial da propaganda cristã:

O termo “Cruzada” também é utilizado para designar qualquer guerra religiosa ou mesmo um movimento político ou moral. As Cruzadas tiveram papel de grande importância na propagação do Cristianismo, além de estimular os contatos econômicos e culturais para a civilização europeia. Surge com as Cruzadas um dos primeiros marcos daquilo que, mais tarde, seria chamado de propaganda: a identificação por meio de uma "marca" e sua divulgação. Observe que as Cruzadas propagavam a fé. Propagar! (LUPETI, 2000, p. 37)

Pelo menos por quatorze séculos sua propagação era manuscrita, por simbologia e oralidade. E, a posteriori, utilizaram meios alternativos e duradouros provenientes do ambiente midiático de cada época, visto que a igreja estava preocupada em perpetuar a mensagem além de transmiti-la. Essa importância com as mídias foi considerada principalmente no pontificado de Paulo VI, tanto que o Papa oficializou e documentou o dia 7 de maio de 1967 como o primeiro dia mundial das comunicações sociais:

Com esta iniciativa, proposta pelo Concílio Vaticano II, a Igreja, que "se sente intimamente solidária com o gênero humano e com a sua história”, (Gaudium et spes, Proêmio) quer chamar a atenção dos seus filhos e de todos os homens de boa vontade para o vasto e complexo fenômeno dos modernos meios de comunicação social, como a imprensa, o cinema, o rádio e a televisão, que são uma das notas mais caraterísticas da civilização moderna.

Graças a essas maravilhosas técnicas, a convivência humana assumiu dimensões novas: o tempo e o espaço foram superados, e 0 homem tornou-se um cidadão do mundo, coparticipante e testemunha dos acontecimentos mais distantes e das vicissitudes de toda a humanidade. (PAPA PAULO VI, 1967)

Outro dado que comprova essa integração de mídia e religião é a instituição do Centro Televisivo do Vaticano (CTV) em 1983 (LA SANTA SEDE, [200-?]). Em 1996, o CTV foi oficialmente ligado à Santa Sé cuja proposta desde então era propagar e documentar suas atividades de evangelização. Entre seus serviços, destacam-se as transmissões diretas em eventos anuais do Vaticano e viagens do Papado pelo mundo; serviços diários do Papa e dos principais acontecimentos ligados à Santa Sé e distribuídos para outras emissoras de televisão; produções audiovisuais de documentários sobre o papado e as basílicas romanas; e, por fim, um arquivo acessível às emissoras e produtores, ou seja, uma videoteca com documentações gravadas desde 1984 sobre imagens do pontificado e atividades específicas. Tudo para contribuir com essa universalidade pastoral da igreja e comunicar o evangelho pelos meios de comunicação de cada era. 


\section{PAPA FRANCISCO E A MÍDIA}

Mesmo o clero adquirindo uma forma particular de comunicar-se e administrar sua igreja entre conservadorismos e resistências em cada mandato, com Jorge Mario Bergoglio mudanças consideráveis começaram a aparecer. Sua presença estava não só em televisão, rádio, revista ou jornal, mas também na mídia digital. Um Papa latino, disposto a adaptar as normas da igreja à realidade da sociedade sem imposições, mas com diálogo, enfrentando opiniões conservadoras, discussões e tabus até então velados pelos líderes religiosos.

Papa Francisco assumiu sua posição em 13 de março de 2013 (BIOGRAFIA..., [200-?]) quando foi eleito pelo conclave após a renúncia de Bento XVI. A partir dali mudanças fronteiriças da maior representação católica foram discutidas. Francisco deixou explícito desde sua posse que veio para combater o pensamento tradicional. Sua comunicação foi propagar o evangelho de Jesus Cristo, a humildade, a aceitação às diferenças sem exclusões. Seu desejo era manter contato com os fiéis, doentes e a pobreza, desde suas pregações até sua forma de vestir: renunciou trajes e sapatos típicos optando por uma vestimenta simples e discreta. E também levar à discussão problemas e tabus sociais que $\mathrm{a}$ própria igreja recusava.

Em 11 de março de 1958, Francisco ingressou na Companhia de Jesus, conhecida como Congregação Jesuíta, o que provocou questionamentos entre fiéis e estudiosos. Isso porque essa organização surgiu inspirada na formação militar, cujo propósito era abolir o surgimento do protestantismo liderado por Martin Lutero.

Entre os séculos XVI e XVIII, a Companhia de Jesus (FREIRE, 2011), criada pelo espanhol Inácio de Loyola, exerceu um poder repentino no catolicismo pregando a fé católica e a obediência ao papado. Em meio a combates, conquistou e doutrinou novos adeptos até então contrários ao cristianismo desenvolvendo inúmeras obras na área da educação por um método controlador e radical. Em 1773, ao sentir-se ameaçada pela força e poder que os jesuítas conquistaram, a Igreja Católica extinguiu a ordem substancialmente. Mas, em 1814, Papa Pio VII reconheceu novamente sua importância e reestruturou a companhia.

Séculos depois, ao admitir a perda crescente de católicos para outras doutrinas pela dissonância entre a comunicação dos papas anteriores com as mudanças culturais do fiel, mais uma vez confirmada com a renúncia de Bento XVI, alguns líderes apostaram na necessidade de um jesuíta assumir o papado (OS JESUÍTAS... 2013). Isso não deixa de ser mais uma travessia de fronteiras pois, pela primeira vez na história, a ordem obteve um representante indicado para o maior cargo da Igreja Católica. Por outro lado, a apreensão de alguns grupos permaneceu devido a esse histórico que Francisco traz em seu currículo, cercado de fatos provocados pela sua congregação jesuítica.

Em 27 de junho de 2015, o Papa criou novas alternativas de aproximação reformulando o setor interno de comunicação do Vaticano. Instituiu a Secretaria para a Comunicação (ARQUIDIOCESE DE SÃO PAULO, 2015) estabelecendo novos organismos, incluindo o serviço de administração digital: Pontifício Conselho das Comunicações Sociais; Sala de Imprensa da Santa Sé; Serviço Internet Vaticano; Rádio Vaticano; Centro Televisivo Vaticano; L’Osservatore Romano; Tipografia Vaticana; Serviço Fotográfico; Livraria Editora Vaticana (ARQUIDIOCESE DE SÃO PAULO, 2015). 
$\mathrm{O}$ atual contexto comunicativo, caracterizado pela presença e pelo desenvolvimento das mídias digitais, pelos fatores da convergência e da interatividade, requer uma reformulação do sistema informativo da Santa Sé e uma reorganização que proceda decididamente rumo a uma integração e gestão unitária. (apud ARQUIDIOCESE DE SÃO PAULO, 2015)

Francisco tem-se manifestado com certa relevância nos canais Twitter, Youtube, Facebook e Instagram. Faz-se aqui, então, uma análise da sua comunicação no aplicativo Instagram.

\section{O Instagram}

Para empresas, marcas e instituições, o objetivo do aplicativo Instagram possibilita uma proximidade com seu público para impulsionar marcas e personalidades.

O Instagram surgiu para o público em 2010 tendo como fundador o norte-americano Kevin Systrom e cofundador o brasileiro Mike Krieger (OLIVEIRA, 2014). A princípio, o aplicativo tinha acesso apenas em sistemas operacionais da Apple, como o iPhone. Em 2012 foi disponibilizado para dispositivos populares como o Android, do Google, com cerca de um milhão de downloads pela loja virtual de aplicativos, o Google Play. Após a compra pelo Facebook, a plataforma atingiu seu ápice rapidamente e hoje ultrapassa cem milhões de usuários mundialmente.

Quanto às funcionalidades, o usuário precisa cadastrar um perfil para utilizar a plataforma. Em seguida, pode capturar e compartilhar fotos em formato 4:3, inserir filtros para melhoramento da imagem, além de alguns efeitos. Também é possível publicar e compartilhar vídeos de até um minuto, aplicar filtros específicos para corrigir imperfeições de imagem e o usuário tem a possibilidade de utilizar referências com marcações do caractere "\#” 1 sucedidas por alguma palavra-chave caso queira ser localizado em pesquisas com estas palavras específicas. Permeado através dos computadores, notebooks, tablets ou smartphones, o Instagram pode ser classificado como uma rede que conecta trocas, emoções e interações entre usuários em discussões criadas em torno de imagens (PIRES, 2012).

\section{PAPA FRANCISCO, 0 INSTAGRAME AS MULHERES}

Em entrevista concedida a Borneli (2016), Papa Francisco colocou que a internet é uma "dádiva de Deus". Usando-as com sabedoria, o religioso afirma que são maneiras humanas de comunicar-se, observada à autonomia do indivíduo: "Não é a tecnologia que determina se a comunicação é ou não autêntica, mas sim o coração humano e a nossa capacidade de usar sabiamente os meios à nossa disposição".

Em reportagem publicada no Jornal do Brasil (PAPA..., 2016), no dia 21 de março de 2016, o líder conquistou 1,5 milhão seguidores no aplicativo Instagram em apenas três dias. As primeiras publicações no perfil @ franciscus mostram detalhes das ações do pontificado, bem como suas reações emocionais em momentos de introspecção, encontro com fiéis, discursos, cuja ideia do perfil é estabelecer certa intimidade comunicando suas mensagens. "Escolheremos algumas fotos feitas pelo serviço fotográfico, que enfatizem os aspectos de proximidade e de inclusão

1. Leia-se "jogo da velha" ou "cerquilha". 
que o Papa Francisco vive todos os dias”, informou Dario Viganò (apud PAPA..., 2016), diretor da Secretaria para as Comunicações do Vaticano à rádio da mesma rede.

\section{ANÁLISE DE COMENTÁRIOS DAS MULHERES SEGUIDORAS EM DOIS VÍDEOS DO PERFIL @FRANCISCUS}

Para exemplificar e analisar a prática comunicacional de Francisco no Instagram, são utilizados dois vídeos específicos, sendo que o primeiro é o anúncio da inauguração do Papa no aplicativo (Figura 1). Já o segundo, uma mensagem invocativa convidando seus seguidores a uma missão ligada ao seu projeto de evangelização.

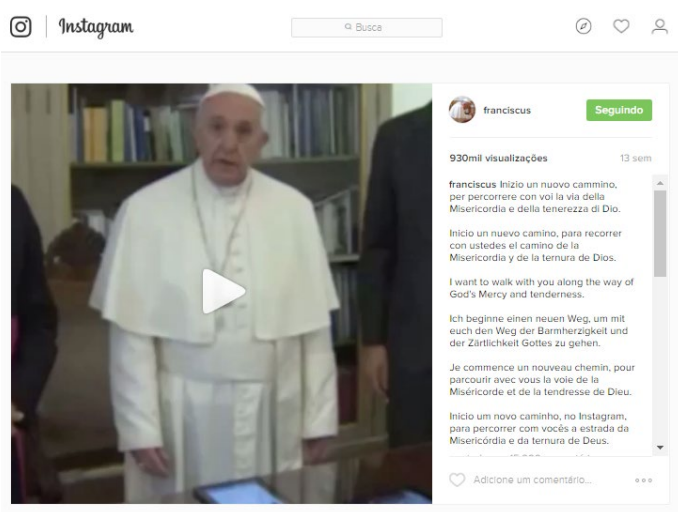

Figura 1. Vídeo do Papa Francisco no Instagram².

Esse foi o primeiro material audiovisual publicado em seu perfil. Francisco dirige-se diretamente a seu público e anuncia o início de sua conexão com uma mensagem objetiva: "Inicio um novo caminho, no Instagram, para percorrer com vocês a estrada da Misericórdia e da ternura de Deus”3. Nota-se em suas palavras a sensação de proximidade com seu público, a ideia de intimidade. Da mesma forma o fiel que, conectado, sente-se perto do religioso. Esse vídeo obteve mais de 930 mil visualizações e 15.900 comentários, totalizando treze semanas (de março a junho de 2016).

Como critério de amostragem, foram coletados os trezentos últimos comentários desse vídeo para fins de análise, incluindo as línguas portuguesa, inglesa, espanhola e italiana. Dessas, 232 eram mulheres e 68 homens, o mostra que nessa amostragem a maior parte dos comentários é das mulheres. Quanto ao conteúdo dos comentários, 132 indicaram o vídeo para outros contatos e 168 comentaram com mensagens positivas, felicitações, orações e agradecimentos:

Que presente Deus nos enviou: Papa Francisco!! Percorremos juntos esta estrada. (Mulher 1)

Obrigada meu bom Francisco, amado Papa. Caminhemos juntos, ter o senhor assim tão perto é animador! Obrigada por estar sempre ao nosso lado, que Deus o abençoe e Maria o guarde. Rezo por ti! (Mulher 2)

2. Disponível em: <https://goo.gl/AVY9Zf >. Acesso em: 15 jun. 2016.

3. Mensagem descritiva no vídeo e traduzida em seis principais línguas: italiana, espanhola, inglesa, alemã, francesa e portuguesa. 
Oi Papa gostaria de receber uma mensagem de paz do Sr. se possível! @franciscus que Deus o abençoe. (Mulher 3)

Eres un padre celestial aquí en la tierra papa Francisco. (Mulher 4)

Que alegria estar, ao menos pelo instrumento da rede social, mais perto de ti! Mas sei que na oração não há distância! O próprio Deus vem até nós. Ele está em nós!!! Que Deus sempre o conduza, Santo Padre! Rezando por ti! Sua bênção. Shalom. (Mulher 5)

Nosso Chico é Show. (Homem 1)

Que a Santíssima Trindade lhe proteja sempre. Acredito no Papa. Amém. (Homem 2)

$\mathrm{Tu}$ vieste para homogeneizar a síntese divina! Todos estão convosco. (Homem 3)

Observando os comentários, percebe-se a reciprocidade dos fiéis diante dessa atividade. Nota-se que esse primeiro vídeo já possibilitou um diálogo aberto e o início da cultura do engajamento, fazendo com que haja uma separação de fronteiras, o que antes era incapaz de observar uma autoridade papal do catolicismo estar tão perto de seus seguidores. Isso diferencia dos papas anteriores confirmando o que sua congregação tem como propósito: conquistar e evangelizar fiéis indo a seu encontro e mantendo diálogo íntimo, aberto, com o auxílio da cultura digital e participativa.

Significa também que o vídeo atingiu seus objetivos. A descrição do diálogo em textos de até seis línguas facilita mais ainda a interatividade com seguidoras de vários continentes (Figura 2).

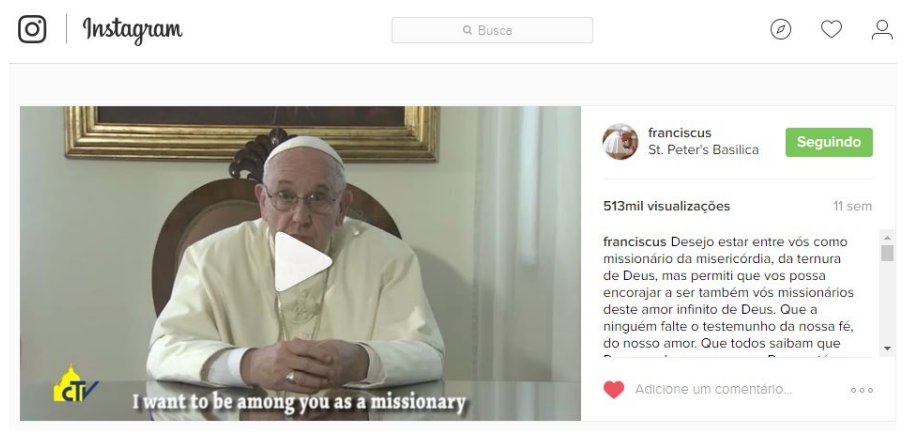

Figura 2. Vídeo com mensagem do Papa aos fiéis ${ }^{5}$

Esse vídeo foi o quarto material publicado no perfil @franciscus. Numa postura um tanto direta, Francisco comunica na mensagem o seu objetivo e o desejo de comunicação com os fiéis:

Desejo estar entre vós como missionário da misericórdia, da ternura de Deus, mas permiti que vos possa encorajar a ser também vós missionários deste amor infinito de Deus. Que a ninguém falte o testemunho da nossa fé, do nosso amor. Que todos saibam que Deus perdoa sempre, que Deus está sempre ao nosso lado, que Deus nos ama ${ }^{6}$.

Com duração de quarenta segundos, o vídeo foi gravado em língua espanhola e legendado em inglês. Mais uma vez é notável em suas

4. Disponível em: <https://goo.gl/AVY9Zf>. Acesso em: 15 jun. 2016.

5. Disponível em: <https://goo.gl/KXfHCf $>$. Acesso em: 15 jun. 2016.

6. Mensagem descritiva no vídeo e traduzida em quatro línguas: italiana, alemã, francesa e portuguesa. 
palavras a proximidade estabelecida com os fiéis. O vídeo obteve mais de 513 mil visualizações e 4.980 comentários em 13 semanas (de março a junho de 2016).

Assim como no vídeo anterior, no tocante ao critério de amostragem, foram coletados também os trezentos últimos comentários para fins de análise. Destes, 222 eram mulheres e 78 homens. Observa-se também que a maior parte dos comentários é feito por mulheres. O vídeo foi indicado 136 vezes para outros contatos e 164 pessoas o comentaram. Em relação ao vídeo anterior, nota-se que a frequência de menções e quantidades totais entre homens e mulheres são semelhantes. Nesse vídeo, a maioria dos comentários também são felicitações, orações e reflexões:

Amém! Que Deus te abençoe Papa Francisco, suas mensagens alimentam meu coração e aumentam mais ainda minha Fé em Deus. Obrigada! @franciscus. (Mulher 1)

Gracias por este mensaje tan importante y por ser nuestra inspiración! (Mulher 2)

You have drawn me back into the church. Your warm spirit and open heart brings me peace. It's an honor to hear you speak and one day I hope to meet you. (Mulher 3)

Amém [m] eu querido, obrigada por se fazer sempre presente entre nós! O Brasil te ama muitoooo Santo Padre! (Mulher 4)

Amém, reze por mim pela minha recuperação física, sua bênção Papa Francisco. (Mulher 5)

Amém. Obrigado, querido Papa. "Doce Jesus na terra”. Como dizia Santa Tereza de Calcutá. (Homem 1)

Ayude a Venezuela, estamos pasando hambre. (Homem 2)

Dios te bendiga siempre. (Homem 3$)^{7}$

Nesses comentários, confirma-se a comunicação de seguidoras e seguidores diante do vídeo. Francisco iniciou o vídeo reforçando sua função: ser missionário, levar a mensagem evangelizando. Em seguida, continuou com uma mensagem de aconselhamento e convite para essa missão, evidenciando a permanência da fé e do amor. E finaliza a mensagem com um recado de esperança e consolo a respeito de Deus.

Ao observar as reações dos fiéis, verifica-se que a comunicação desse vídeo também atingiu seus objetivos. A acessibilidade do Papa aliou-se à sensação de proximidade e conquistou uma interatividade positiva entre milhares de seguidores e, principalmente, seguidoras.

\section{CONSIDERAÇÕES FINAIS}

A partir deste trabalho, apenas introdutório, finaliza-se a análise da interatividade do Papa Francisco e a igreja na mídia digital, especialmente no aplicativo Instagram. Foi válido abordar como o Vaticano e o catolicismo observam os meios de comunicação de cada era e como utilizam-se desses recursos para aproximar-se das pessoas. Verificouse pela metodologia da análise de conteúdo como isso foi apresentado historicamente, especialmente na rede digital. Observou-se também a perspectiva de Papa Francisco sobre essas rupturas culturais na mídia, o que incentiva essa facilidade do ingresso digital na igreja: os meios de comunicação surgem para servir e aproximar pessoas. Observando

7. Disponível em: <https://goo.gl/KXfHCf>. Acesso em: 15 jun. 2016. 
os comentários dos vídeos no aplicativo Instagram, os fiéis interagem, participam, solicitam orações. Há uma troca de emoções, conforto, bemestar, questionamentos, partilha das mensagens sem barreiras ou censura entre fiel e autoridade católica.

Também foi observado que Papa Francisco utiliza também dessa mídia e seus recursos de foto e vídeo para propagar suas mensagens, informações, mostrar exemplos de introspecção e encontro pessoal com outros fiéis. O Papa sabe se comunicar com essas mídias. Seu objetivo sempre foi passar a imagem de comunicar com facilidade a cultura do encontro com seus próprios exemplos, com uma linguagem popular, informal e de fácil entendimento.

A imagem pública de um Papa inalcançável nas mídias sociais mudou culturalmente o pensamento de muitos conservadores que até então não concebiam. A ideia de um papa estar presente nesse ambiente possibilitou críticas e certo estranhamento, mas também elogios e felicitações por adotar estas iniciativas. Isso fez com que ele atingisse um público diferenciado, o público da sociedade em rede dito por Castells (1999). Portanto, não teria como desviar-se dessa realidade, já que o objetivo da igreja é atrair fiéis em virtude de tantas perdas.

Claro que a cultura de fé de Francisco, suas ações, a forma como se relaciona com os fiéis, sua espiritualidade e sua história contribuem para essa força. Com isso Papa Francisco leva mensagens de esperança, positividade e conforto para muitas famílias. Assim, conforme as temáticas levantadas na análise teórica e empírica sobre o meio digital e a religião, compreende-se a nova evangelização e as novas formas de comunicação católica na mídia, mais realista e dinâmica. Portanto, este trabalho científico teve o intuito de colaborar com o conhecimento de pesquisadores, teólogos, comunicadores, sociólogos, estudantes e demais interessados no tema, pois é importante discutir essas mudanças de fronteiras na igreja, especialmente dentro da comunicação. E é lançado o desafio de prosseguir o estudo, provocar discussões e acompanhar este trabalho.

\section{REFERÊNCIAS}

ARQUIDIOCESE DE SÃO PAULO. Papa Francisco cria Secretaria para Comunicação. Arquidiocese de São Paulo Notícias, São Paulo, 27 jun. 2015. Disponível em: <https://goo.gl/ mHXhN5>. Acesso em: 15 jun. 2016.

BARDIN, L. Análise de conteúdo. Lisboa: Edições 70, 2009.

BIOGRAFIA do Santo Padre Francisco. A Santa Sé, Vaticano, [200-?]. Disponível em: <https://goo.gl/T2nRWY>. Acesso em: 14 jun. 2016.

BORNELI, J. Papa Francisco: internet, redes sociais e mensagens de texto são "dádivas de Deus". StartSe, São Paulo, 22 jan. 2016. Disponível em: <https://goo.gl/YNHiJ1>. Acesso em: 14 jun. 2016.

CASTELLS, M. A Sociedade em rede. 14. ed. São Paulo: Paz e Terra, 1999.

COELHO, L. A. (Org.). Conceitos-chave em design. Rio de Janeiro: PUC-Rio; Ribeirão Preto: Novas Ideias, 2008.

FREIRE, L. G. L. Fontes históricas jesuíticas: manuscritos do arquivo histórico ultramarino catalogados pelo Projeto Resgate. Cadernos de História da Educação, Lisboa, v. 10, n. 1, jan./jun. 2011. Disponível em: <https://goo.gl/8N7UXJ>. Acesso em: 14 jun. 2016.

KELLNER, D. A cultura da mídia: estudos culturais, identidade e política entre o moderno e o pós-moderno. Bauru: Edusc, 2001.

LA SANTA SEDE. Centro Televisivo do Vaticano. Vaticano, [200-?]. Disponível em: <https:// goo.gl/zbAwNJ>. Acesso em: 14 jun. 2016. 
LAVILLE, C.; DIONNE, J. A construção do saber. Belo Horizonte: UFMG, 1999.

LUPETI, M. Planejamento de comunicação. São Paulo: Futura, 2000.

MAREK, R. Creativity meets circulation: internet videos, amateurs and the process of evolution. In: FISCHER, G.; VASSEN, F. (Ed.). Collaborative work in the sciences, literature and the arts. Amsterdam: Rodopi, 2011.

OLIVEIRA, Y. R. O Instagram como uma nova ferramenta para estratégias publicitárias. In: CONGRESSO DE CIÊNCIAS DA COMUNICAÇÃO NA REGIÃO NORDESTE, 16., 2014, João Pessoa. Anais... João Pessoa: Universidade Federal da Paraíba, 2014. Disponível em: <https://goo.gl/aUGkPG>. Acesso em: 16 jun. 2016.

OS JESUITAS contra-atacam. Superinteressante, São Paulo, 2 jul. 2013. Disponível em: <https://goo.gl/sUXQsy>. Acesso em: 15 jun. 2016.

PAPA Francisco alcança 1,5 milhão de seguidores no Instagram. Jornal do Brasil, Rio de Janeiro, 21 mar. 2016. Disponível em: <https://goo.gl/g2UdD5>. Acesso em: 14 jun. 2016.

PAPA PAULO VI. Os meios de comunicação social. Vaticano, 1967. Disponível em: <https:// goo.gl/mQfrwc>. Acesso em: 14 jun. 2016.

PIRES, G. T. S. Fotografia através de dispositivos móveis: estudo de caso sobre o Instagram. 2012. 76 f. Trabalho de Conclusão de Curso (Bacharelado em Publicidade e Propaganda) - Faculdade de Comunicação Social, Pontifícia Universidade Católica do Rio Grande do Sul, Porto Alegre, 2012.

SILVA, S. A Igreja Católica e os meios de comunicação: um planejamento de comunicação para a Catedral Metropolitana de Juiz de Fora. Juiz de Fora: Universidade Federal de Juiz de Fora, 2006. Disponível em: <https://goo.gl/C6ujkU>. Acesso em: 14 jun. 2016.

TIETZMANN, R; ROSSINI, M. O registro da experiência no audiovisual de acontecimento contemporâneo. In: ENCONTRO ANUAL COMPÓS, 22., 2013, Salvador. Anais... Salvador: Universidade Federal da Bahia, 2013. 